\title{
Cannibalism and Virus Production in Spodoptera frugiperda (J.E. Smith) (Lepidoptera: Noctuidae) Larvae Fed with Two Leaf Substrates Inoculated with Baculovirus spodoptera
}

\author{
FH Valicente, es Tuelher, RC Pena, R Andreazza, Mrf Guimarães \\ Embrapa Milho e Sorgo, Sete Lagoas, MG, Brasil
}

\section{Keywords \\ Biopesticide, food source, larval age, nucleopolyhedrovirus, occlusion bodies production}

\section{Correspondence}

FH Valicente, Embrapa Milho e Sorgo, Caixa Postal 151, Sete Lagoas 35701-970, MG, Brasil; fernando.valicente@embrapa.br

Edited by Madelaine Venzon - EPAMIG

Received 24 May 2012 and accepted 5 January 2013

Published online 29 January 2013

(C) Sociedade Entomológica do Brasil 2013

\begin{abstract}
Cannibalism in the fall armyworm, Spodoptera frugiperda (J.E. Smith) (Lepidoptera: Noctuidae) (FAW), is a limiting factor in a baculovirus production system. To detect the impact of cannibalism, a two-step bioassay was conducted with different larval ages of FAW fed on two food sources (corn and castor bean leaves) contaminated with the $S$. frugiperda multiple-embedded nucleopolyhedrovirus. In a first bioassay, the food source affected the cannibalism, being higher for all larval ages tested (5-, 6- and 7-day-old larvae) in larvae fed on corn than on those fed on castor bean leaves. Larval mortality, weight equivalent and larval equivalents (LEs) per hectare decreased as the larval age increased. Larval weight, occlusion bodies (OBs)/larva and total OBs increased when the larval age increased. In a second bioassay, in which only 6and 7-day-old larvae were used because of the performance in the first bioassay, the cannibalism rates were affected by the interaction between food sources and time of feeding ( 48 and $72 \mathrm{~h}$ ), reaching the highest values for 6- and 7-day-old larvae fed on corn leaves for $72 \mathrm{~h}$. Mortality of the FAW was affected by the interaction between food sources, larval age and time of feeding. The lowest mortalities were on 7-day-old larvae when they were fed on castor bean leaves for 48 and $72 \mathrm{~h}$. Larval weight, OBs/larva, total OBs and LEs were affected by the interaction between food sources and larval age. A significant correlation was observed between larval weight and OBs/larva that fed on both food sources, suggesting that larval weight can be used to achieve a concentration to be sprayed in 1 ha.
\end{abstract}

\section{Introduction}

The fall armyworm Spodoptera frugiperda (Smith) is responsible for significant losses to corn production. Its control is mainly achieved using chemical insecticides. However, biological control using a Baculovirus-multipleembedded nucleopolyhedrovirus (SFMNPV) may become a viable alternative to control this insect in the field. SfMNPV has been reported to be one of the most prevalent entomopathogen in natural populations (Gardner \& Fuxa 1980) and can be an effective tool to control fall armyworm in the field (Fuxa 1991, Valicente \& Costa 1995, Cruz et al 1997, 2002). Large-scale production of this baculovirus is still obtained in vivo by infecting healthy larvae, which is influenced by many factors such as host, virus inoculum, incubation conditions and production methods (Shapiro 1986, Hunter-Fujita et al 1998). However, two major problems have limited the large-scale production of baculoviruses specific to fall armyworm. First, baculoviruses that infect fall armyworm have a unique characteristic of causing the liquefaction of the integument as soon as the larvae are dead. In a large-scale production system, this makes the 
process laborious and the final product expensive. This constraining factor is important because all larvae must be frozen immediately after death, to allow harvesting with some degree of success. As a consequence, a great amount of the internal liquid containing occlusion bodies (OBs) is lost. As larval equivalents are defined as the amount required to reduce crop loss or pest population below economic threshold [larval equivalents (LEs per hectare)] (Federici 1999), the loss of occlusion bodies before the larvae is processed leads to an increased number of larvae to be produced and used to be sprayed per hectare.

The second factor is the cannibalistic behaviour of the fall armyworm. This requires larval individualization, which is labour-intensive, increases the risk of contamination and increases the costs of the biopesticide produced. Cannibalism is quite common among larvae of Lepidoptera (Pierce 1995, Reed et al 1996), and often produces deep impacts on population dynamics (Elgar \& Crespi 1992). Lepidopterans that develop at high densities may have altered susceptibility to infection by viruses (Goulson \& Cory 1995, Reeson et al 2000), which is commonly observed under laboratory rearing even when alternative food is not limiting, accounting for 40-60\% mortality (Chapman et al 1999). Cannibalism and larval density can affect largescale virus production systems, and it may affect the susceptibility to infection caused by viruses in Lepidoptera that develop at high densities (Goulson \& Cory 1995, Reeson et al 2000). In addition, it may reduce the number of virusinfected larvae and the amount of virus produced (Moscardi et al 1997). There are also some discussions on the role of host plant on the susceptibility of lepidopterans to Baculovirus (Santiago-Alvarez \& Ortiz-Garcia 1992, Ali et al 2002), and on the role of cannibalism on the risk of SfMNPV horizontal transmission (Chapman et al 1999). However, the influence of different host plants on fall armyworm cannibalism was not reported yet.

Therefore, we tested an SfMNPV isolate that doesn't cause the liquefaction of the integument of dead larvae immediately after death (Valicente et al 2008) in a twostep bioassay, the cannibalistic behaviour and the tritrophic interaction of fall armyworm fed on two food sources, corn (Zea mays) and castor bean (Ricinus communis) leaves inoculated with SfMNPV in a simulation of a large-scale production system.

\section{Material and Methods}

\section{Insect colony and virus stock}

A colony of $S$. frugiperda was maintained at $25 \pm 2^{\circ} \mathrm{C}, 65-80 \%$ relative humidity $(\mathrm{RH})$ and $14 \mathrm{~h}$ photophase. Larvae were reared on an artificial diet as in Valicente \& Barreto (2003).
All experiments were conducted under the same rearing conditions, photoperiod and RH. The SfMNPV isolate was obtained from a natural epizootic in a field population of $S$. frugiperda collected in Sete Lagoas, Minas Gerais, Brazil and has been characterized as isolate 6 , a unique strain that does not cause the liquefaction of the larval integument immediately after larval death (Barreto et al 2005, Valicente et al 2008).

Dead larvae were collected daily and stored at $-18^{\circ} \mathrm{C}$ for purification of the occlusion bodies (OBs). Virus was extracted by macerating dead larvae in TE buffer, $\mathrm{pH} 8.0$ (10 mL/L $0.1 \mathrm{M}$ Tris- $\mathrm{HCl}$ and $2 \mathrm{~mL} / \mathrm{L} 0.5 \mathrm{M}$ EDTA). The macerate was later filtered through a layer of cheese cloth, and the filtrate was centrifuged twice $(11,952 \mathrm{~g} \times 15 \mathrm{~min})$. The resulting pellet was resuspended in $2 \mathrm{~mL}$ of sterile distilled water, layered onto a 19.5, 18.75, 18.0 and $17.9 \mathrm{~g} / 15 \mathrm{~mL}$ sucrose gradient, followed by centrifugation $\left(103,700 \mathrm{~g} \times 40 \mathrm{~min} \times 4^{\circ} \mathrm{C}\right)$. The viral band was collected followed by another centrifugation in buffer $(11,952 \mathrm{~g} \times$ $15 \mathrm{~min}$ ). The final pellet was resuspended in sterile distilled water, and the virus suspension was stored at $-18^{\circ} \mathrm{C}$.

\section{Effects of food source on larval cannibalism and virus production}

Two host plants infected with SfMNPV, corn (Zea mays) and castor bean (Ricinus communis) leaves were tested to estimate the effect of the food source on the larval cannibalism rate of $S$. frugiperda, as well as on virus production. The effect of the food source on virus production was determined by assessing the weight of the dead larvae and the total amount of OBs produced, as parameters to quantify the larval equivalent per hectare (LE) and weight equivalent (WE) per hectare. The experimental protocol was a randomized block design composed of six treatments resulting from the combination of two types of plant leaves and three larval ages. Three experimental blocks were done, and each one was considered one replicate. Leaves of corn and castor bean were sprayed with $1.35 \times 10^{6}$ $\mathrm{OBs} / \mathrm{mL}$ of SfMNPV in distilled water, containing $6.37 \pm$ $0.5 \mathrm{mg}$ of Tween $2 \mathrm{O}^{\circledR}$ (Merck Schuchardt, Germany). Control treatment sprayed only with distilled water and Tween was used only to compare the cannibalism between healthy and infected larvae and to correct mortality by causes other than the virus infection. Leaves were previously washed with $5 \mathrm{~mL} / \mathrm{L}$ of sodium hypochlorite, rinsed with water and provided ad libitum to 5-, 6- and 7-day-old larvae in groups of 300 larvae/replicate/treatment placed in a 4-L plastic jar, closed with a thin cloth and maintained under laboratory conditions $\left(25.0 \pm 1^{\circ} \mathrm{C}, 60.0 \pm 10 \% \mathrm{RH}\right.$, and a 14 -h photophase). Cannibalism was checked $48 \mathrm{~h}$ later, and all living larvae were individualized in $50-\mathrm{mL}$ plastic containers. Larval mortality was checked daily from the 
seventh day after contamination until death or pupation. Dead larvae were harvested and stored at $-18^{\circ} \mathrm{C}$ for further analysis. To quantify the $\mathrm{OB}$ production, dead larvae were weighted, macerated with distilled water, filtered through a cheese cloth and the number of OBs quantified after serial dilutions using a Neubauer hemocytometer. The total number of OBs was used to estimate the LE per hectare and WE per hectare (the average weight of dead larvae needed to achieve $2 \times 10^{11}$ OBs to be sprayed in 1 ha). Because of 5-day-old larvae low performance in producing OBs, we proceeded to the second bioassay, and only 6- and 7-day-old larvae were used, for 48 and $72 \mathrm{~h}$ of exposure to the baculovirus.

\section{Effect of the contamination period on viral production and larval cannibalism}

The experiment was composed of six treatments that resulted from a combination of the two types of food sources (corn and castor bean), two larval ages (6- and 7day-old fall armyworm larvae) and two duration of larval feeding on virus-contaminated leaves (48 and $72 \mathrm{~h}$ ). The experiment was repeated four times at different periods, and each period was considered as one block in the statistical analysis. Groups of 700 S. frugiperda larvae were used per replicate in 20-L plastic recipients. SfMNPV was applied on corn and castor bean leaves at a concentration of $1.55 \times 10^{7} \mathrm{OBs} / \mathrm{mL}$ in a suspension containing $12.74 \pm$ $1.1 \mathrm{mg}$ of Tween $20^{\circledR}$ (Merck Schuchardt, Germany). Control treatments (corn and castor bean leaves) sprayed only with water added of Tween were used only to compare cannibalism between healthy and infected larvae and to correct mortality by causes other than virus infection.

Nearly $4 \mathrm{~cm}^{2}$ of leaf was offered per larva (approximately $2,800 \mathrm{~cm}^{2} / 20$-L plastic containers). The containers were closed with a thin cloth and maintained under laboratory conditions $\left(25.0 \pm 1^{\circ} \mathrm{C}, 60.0 \pm 10 \% \mathrm{RH}, 14 \mathrm{~h}\right.$ photophase). After 48 and $72 \mathrm{~h}$, larvae were counted and individualized in plastic containers of $50 \mathrm{~mL}$ until death or pupation. Larval mortality was checked daily starting 7 days after inoculation, and dead larvae were stored at $-18^{\circ} \mathrm{C}$ for further analysis. The following parameters were evaluated: cannibalism after 48 and $72 \mathrm{~h}$, mortality of individualized larvae, OBs per larvae, LE and WE. The OB production was quantified as earlier described. Treatments were repeated four times.

\section{Statistical analyses}

Larval cannibalism, percentage of mortality from virus, larval weight, OBs per larva, WE and LE per hectare were subjected to analysis of variance followed by post hoc Tukey test $(\alpha=0.05)$ when necessary. LE data from first experiment were normalized by log transformation for analysis, but are reported as non-transformed values. Control data were included only when analysing cannibalism and to correct mortality of virus sprayed treatments by Abbott's formula (Abbott 1925). SAS version 8 (SAS 1999) was used for statistical analyses. All data are reported as means \pm standard error.

\section{Results}

ANOVA with three variation factors and its interactions were performed. Our results showed statistical significance of those factors on the variables analysed, so we decided to discuss the parameters that were significantly different, and not compare all the treatments. Tables 1 and 2 show all the interactions among treatments.

\section{Effects of food source on larval cannibalism and virus production}

The presence or absence of virus did not affect the cannibalism rates of $S$. frugiperda at any larval age or food source $(F=0.32 ; d f=1,22 ; P=0.58)$. Average cannibalism rates were $25.8 \%$ and $27.9 \%$ in the presence or absence of the virus, respectively. Cannibalism rates were only affected by the larval age $(F=9.19 ; d f=2,22 ; P=0.001)$ and food source $(F=20.18 ; d f=1,22 ; P<0.001)$. Cannibalism in larvae that fed on corn leaves was higher than when fed on castor bean leaves at all larval ages tested, being the highest in 7-day-old larvae fed on corn (48.1\%) and on castor bean (25.9\%) leaves, and no difference was found in cannibalism between 5- and 6-day-old larvae (Fig 1a).

Larval mortality of the fall armyworm was affected only by larval age $(F=23.70 ; d f=2,10 ; P<0.001)$, and it ranged from $53.6 \%$ to $82.3 \%$, with no difference between the food sources tested. Larval mortality decreased when the larval age increased for both food sources (Fig 1b).

The weight of the dead, infected larvae was only affected by the age of the larvae exposed to virus infection ( $F=$ 46.58; $d f=2,10 ; P<0.0001)$, and the average larval weight considering both food sources ranged from 39.4 to 158.6 mg if 5- or 7-day-old larvae were subjected to infection, respectively. Regardless of the food source used, dead larvae harvested from 7-day-old larvae subjected to infection were the heaviest (Fig 1c).

The weight equivalent (WE) was a result between the interaction of the food source and larval age $(F=6.31 ; d f=2$, 10; $P=0.01)$. The WE did not differ among larval ages within each food source, varying from 14.0 to $14.4 \mathrm{~g}$ of dead larvae fed on castor bean leaves and from 9.9 to $15.7 \mathrm{~g}$ of dead larvae fed on corn leaves (Fig 1d). Five-day-old larvae showed significant difference, and the WE was higher 


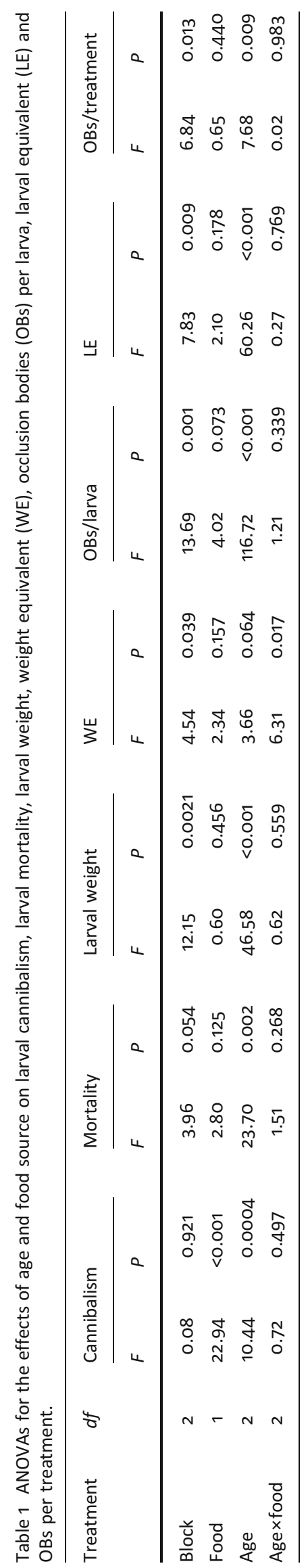

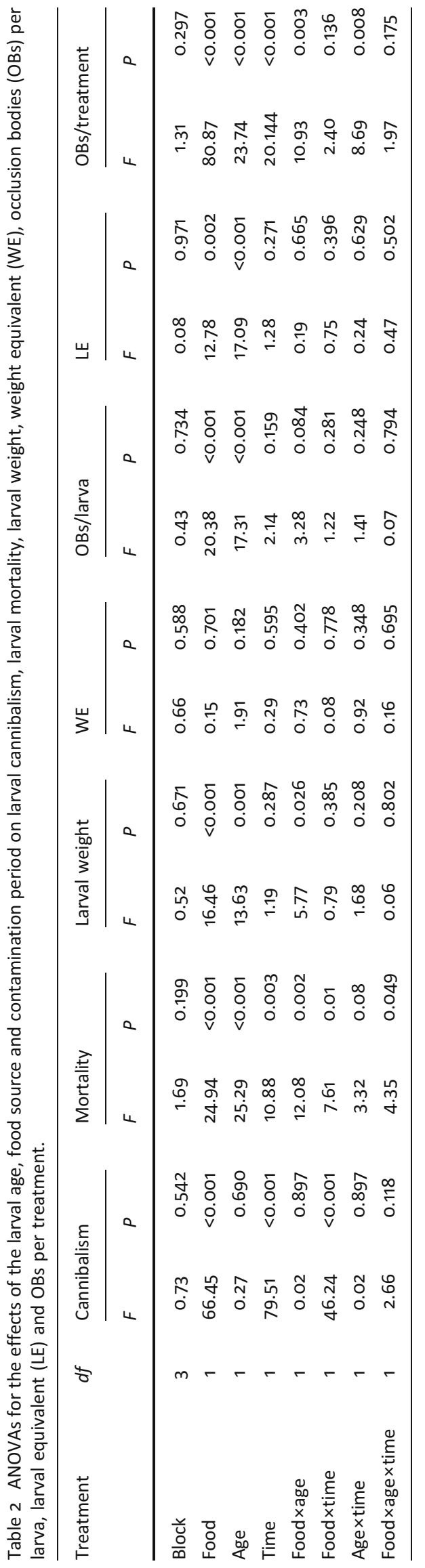



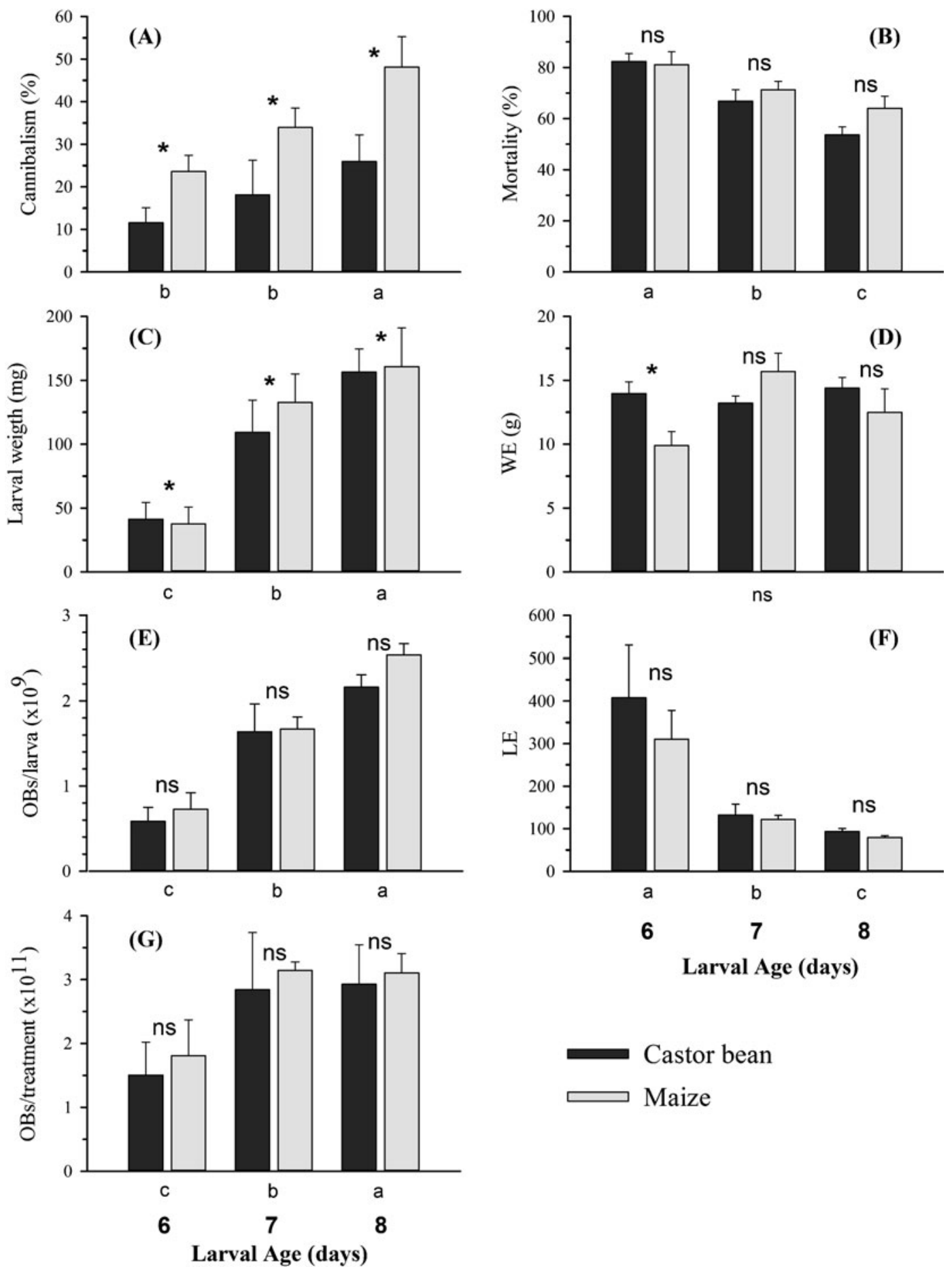

Larval Age (days)

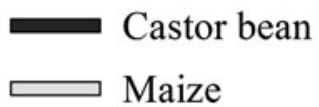

Fig 1 Effect of host plants and larval age upon cannibalism (percentage), mortality (percentage), larval weight (milligrams), weight equivalent (grams), occlusion bodies/larva, larval equivalent and occlusion bodies/treatment. Asterisk $\left({ }^{*}\right)$ upon two bars indicates significant differences between castor bean and maize (Tukey test, $P<0.05$ ). Different letters under the $X$-axis of each graph indicate significant differences among the ages (Tukey test, $P<0.05)$. Columns are average of three replicates, and vertical bars are the standard errors.

when fed on castor bean leaves than when fed on corn leaves. However, no difference was found in 6- and 7-dayold larvae between the two food sources (Fig 1d).

The amount of polyhedra produced per larvae (occlusion bodies $=\mathrm{OB}$ ) was influenced only by the larval age at the time of inoculation $(F=116.72 ; d f=2,10$; $P<0.001)$. The amount of OBs/larva increased as larval age increased, with average values ranging from 0.7 to $2.3 \times 10^{9} \mathrm{OBs} /$ larva to 5 - and 7 -day-old, respectively (Fig 1e). 
The larval equivalent (LE per hectare) was only influenced by the age of the larvae $(F=60.26 ; d f=2,10 ; P<0.0001)$. As the larval age increased, the LE per hectare decreased, with 407.9 LE/ha to 5-day-old larvae fed on castor bean leaves and with 79.4 LE/ha to 7-day-old larvae when fed on corn leaves (Fig 1f). No differences were detected among food sources.

The total amount of polyhedra (OBs) produced per treatment was only influenced by larval age $(F=7.68$; $d f=2,10 ; P<0.01)$. The average of total OB production was higher on 6- and 7-day-old than on 5-day-old larvae, and no differences were observed between larvae fed on castor bean or on corn leaves (Fig 1g).

A positive and highly significant correlation between larval weight and OBs/larva was observed from our data (castor bean, $n=12, r=0.987, T=19.629, P<0.0001$; corn, $n=12$, $r=0.933, T=8.169, P<0.0001)$.

\section{Effect of the contamination period on viral production and larval cannibalism}

The rates of cannibalism in larvae of $S$. frugiperda were affected by an interaction between the food source and the period allowed to feed on virus contaminated leaves $(F=46.24 ; d f=1,21 ; P<0.0001)$. Cannibalism was much higher when larvae were fed on infected leaves by $72 \mathrm{~h}$ if compared to those fed by only $48 \mathrm{~h}$, but the increase in cannibalism as the period allowed for infection was prolonged was observed only in larvae fed on corn leaves, regardless of their age (Fig 2a).

Mortality of the fall armyworm was affected by the interaction between food source, larval age and by the period allowed for infection $(F=4.35 ; d f=1,21 ; P<0.05)$. All treatments showed mortality varying from $74 \%$ to $97 \%$. The lowest mortalities were observed on 7-day-old larvae when fed on castor bean leaves, either for $48 \mathrm{~h}$ (74\%) or 72 h (88\%; Fig 2b).

Larval weight was affected by the interaction between food source and larval age $(F=5.77 ; d f=1,21 ; P<0.05)$. The larval weight was higher for 7- than 6-day-old larvae when fed on castor bean leaves, but no difference was observed when the larvae were fed on corn leaves. Differences in the weight of the larvae between the food sources tested was only observed for 7-day-old larvae, with larvae fed on castor bean leaves being heavier than those fed on corn leaves (Fig 2c). However, no difference in the weight equivalent (WE) was observed, and treatments required from 10.1 to $12.8 \mathrm{~g}$ of dead larvae to achieve the required concentration of baculovirus to be sprayed in 1 ha (Fig 2d).

The number of OBs per larva (Fig 2e) was affected by the food source and larval age. The average number of OBs per larva was higher in larvae fed on castor bean than on corn leaves $(F=20.38 ; d f=1,21 ; P<0.001)$. The amount of OBs/larva increased when larval age increased $(F=17.31 ; d f=1,21$; $P<0.001)$, reaching $2.0 \times 10^{9} \mathrm{OBs} /$ larva in 7 -day-old larvae fed on castor bean leaves for $48 \mathrm{~h}$.

The LE was affected by the food source and larval age. LE per hectare decreased when the larval age increased $(F=17.09 ; d f=1,21 ; P<0.001)$. Also, LE was lower in larvae fed on castor bean leaves than on corn leaves $(F=12.78$; $d f=1,21 ; P<0.01)$, regardless of the time of exposure for infection (Fig 2f).

The total amount of polyhedra (OBs) produced per treatment was influenced by the interaction between food source and larval age $(F=10.93 ; d f=1,21 ; P<0.01)$ and larval age and time of feeding $(F=8.69 ; d f=1,21 ; P<0.01)$. The maximum $\mathrm{OB}$ production was achieved when 7-day-old larvae were fed on castor bean leaves, but no difference was observed for 6- and 7-day-old larvae that fed on corn leaves. The largest number of OBs was found in larvae fed on castor bean leaves at both larval ages (Fig 2g).

\section{Discussion}

Cannibalism, a natural behaviour among many animal species, also occurs in S. frugiperda populations when food is a limiting factor. We also demonstrated that the host plant species can affect the cannibalism behaviour of $S$. frugiperda larvae. The LE per hectare for 5-day-old larvae is the key problem in a large-scale production system because they die too small, and it is very expensive to produce the SfMNPV-based biopesticide. According to Federici (1999), 500 larval equivalents per hectare are needed to Spodoptera exigua NPV, and the author states that the number of LEs required to obtain effective control is critical to determine cost-effectiveness because of the cost of labour and materials that go into virus production. Our results showed that 310.8 and $407.8 \mathrm{LEs} / \mathrm{ha}$ are needed when larvae fed on corn and on castor bean leaves, respectively, for 5-dayold larvae. However, for 6- and 7-day-old larvae, only 121 and 79.4 LEs/ha are respectively needed, when larvae feed on corn leaves.

The presence or absence of baculovirus on leaves that were offered did not affect the cannibalism rates of $S$. frugiperda larvae at any age or food source. Otherwise, when the cannibalism in groups of larvae that fed on contaminated leaves was compared, the cannibalism rates were affected by larval age and the food source. Chapman et al (1999) reported that the probability of cannibalism to occur can be affected by larval stage; however, they did not check cannibalism associated with different host plants. Mortality of fall armyworm in the first bioassay was affected by larval age, and decreased when the larval age increased regardless of the food sources. Our results showed $53.5 \%$ and $64.0 \%$ mortality for 7 -day-old larvae 

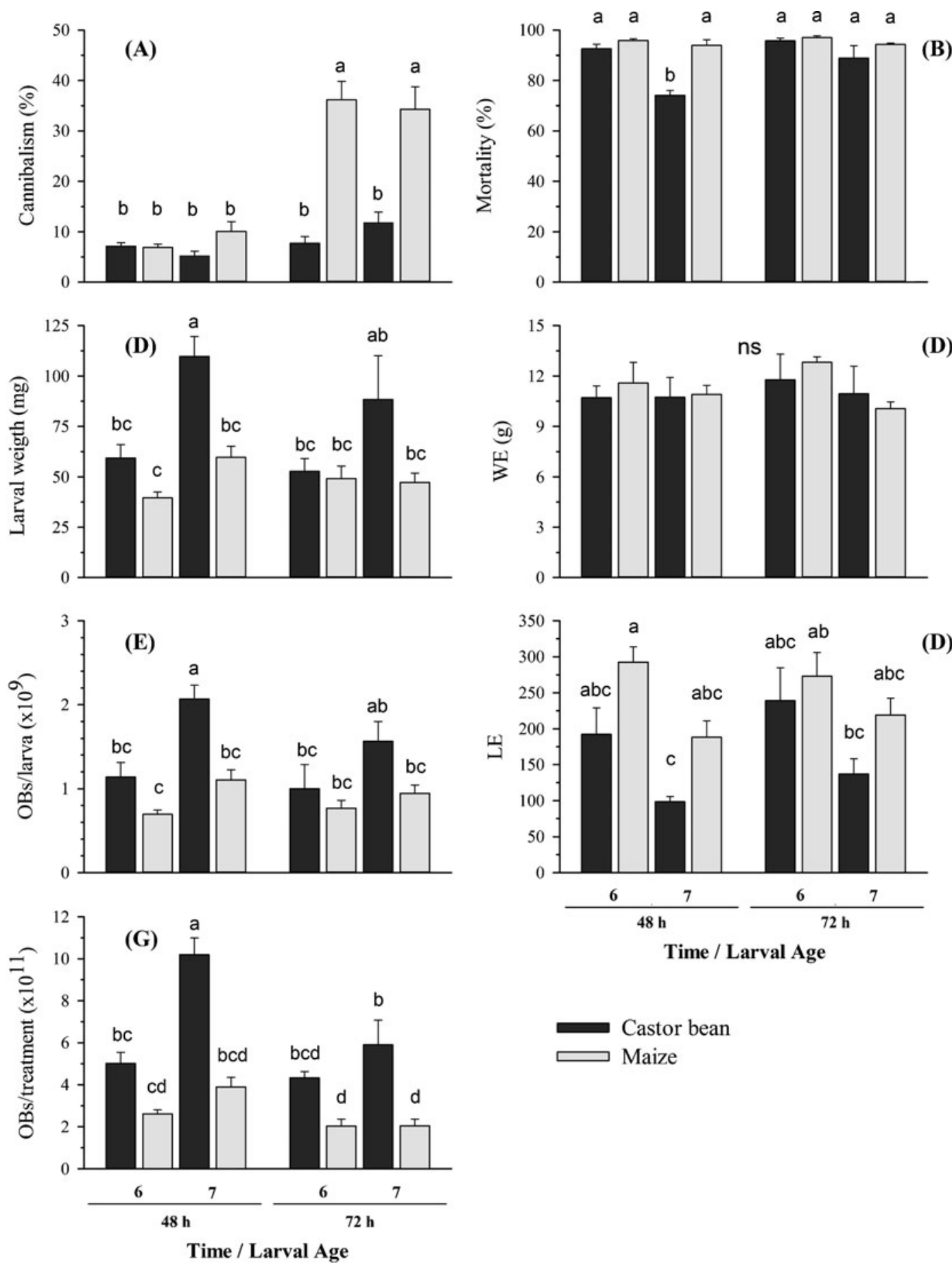

Time / Larval Age

(D)

(D)

B)

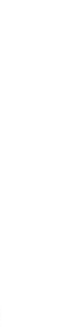


(1992) tested the influence of five host plants on the susceptibility of Spodoptera littoralis (Boisduval) (Lepidoptera: Noctuidae) to a NPV. They found that larvae were significantly less susceptible to the NPV when fed on castor bean than when fed on alfalfa, mulberry, cotton or potato. Nevertheless, they found that the susceptibility of the third instars $S$. littoralis to $S$. littoralis NPV was not statistically different when they were fed on mulberry, cotton or potato. The number of OBs/larva increased when larval age increased, from 5- to 7-day-old, respectively, regardless of the host plant. Our results showed that OB production was least on 5-day-old larvae, and the greatest OB production was $2.5 \times 10^{9} \mathrm{OBs} /$ larva for 7 -day-old larvae fed on corn leaves. The average OB production was greatest on 6- and 7-day-old than in 5-day-old larvae, and the number of OBs produced per treatment was dependent on the larval age, regardless of the host plant. In contrast to our findings, Hodgson et al (2002) showed that the plant species eaten by the host differentially affected the pathogenicity and productivity of two NPV genotypes.

Similarly, the LEs per hectare showed the same tendency as the other parameters, decreasing the number of larvae when larval age increased, reaching values ranging from 407.9 larvae/ha to 5-day-old larvae that fed on castor bean leaves to 79.4 larvae/ha to 7-day-old larvae that fed on corn leaves This is the key factor in a baculovirus-based biopesticide large-scale production, and the LE of 5-day-old dead larvae needed to be sprayed in 1 ha is very high, which it makes the production laborious, and the final product expensive.

We also observed that the rates of cannibalism by larvae of $S$. frugiperda were affected by an interaction between the food source and the time of infection. However, no difference in cannibalism was found for both larval ages when fed in both food sources for $48 \mathrm{~h}$. Nevertheless, our data suggest that no difference in cannibalism was detected when larvae fed on castor bean leaves for $72 \mathrm{~h}$ as compared to $48 \mathrm{~h}$. Our results showed that larval weight was affected by the interaction between food source and larval age interaction. Seven-day-old larvae that fed on castor bean leaves were heavier than those fed on corn leaves. However, 6-day-old larvae showed similar weight when fed on both food sources. Our data suggest that 7day-old larvae should be used in a large-scale production system because it will require a lower LE per hectare than 6-day old larvae.

LE was affected by food source and larval age and decreased when the larval age increased. In addition, LE was lower for larvae that fed on castor bean than those that larvae fed on corn leaves. The number of LE ranged from 98 to a $137 \mathrm{LEs} / \mathrm{ha}$, much lower than the $500 \mathrm{LE} / \mathrm{ha}$ required for $S$. exigua NPV (Federici 1999). The highest number of OBs/larva was observed on larvae fed on castor bean leaves and resulted in a higher amount of OBs as a consequence of the heavier weight of the dead larvae (Fig 1c, e, g). The heavier weight was clearly observed in 7-day-old larvae that were allowed to feed on viruscontaminated food for 48 or $72 \mathrm{~h}$, and no difference was found between 6- and 7-day old larvae that fed on corn leaves, regardless of the period they were allowed to feed on contaminated leaves. Likewise, Raymond et al (2002) found that the yield of OBs was strongly affected by the host plant. A positive and significant correlation was observed between larval weight and OBs/larva that fed on both food sources, indicating that in a large-scale baculovirus production system, the larval weight associated with number of larvae (Les per hectare) generates a good and direct relation to achieve a dose to be sprayed in 1 ha.

Our data suggest that SfMNPV isolate 6 may be successfully used in a large-scale production system. Isolate 6 does not cause the liquefaction of the integument of dead larvae immediately after death, and a low number of larvae, which ranged from 100 to a 150 larvae/ha, is required to achieve a dose to be effective and provide fall armyworm control. The unique characteristic of this baculovirus isolate that does not disrupt the larvae integument also allows the direct use of the weight of the dead larvae to estimate the dose for field application, ranging from 10.75 to $13.86 \mathrm{~g}$ of dead larvae/ha. Besides being efficient in killing fall armyworm, this new baculovirus isolate is easy to harvest. This is one of the most important factors in a biopesticide largescale production system because dead larvae do not need to be frozen before being harvested, reducing laboratory space needed for freezers, leading to a lower energy use. It also lowers the risk of larval contamination and the labour in larvae manipulation. All these factors contribute to reduce the final cost of baculovirus-based biopesticide.

Acknowledgments We would like to thank Celso G. Vieira and Osmar Santana for maintaining the insect culture. We also would like to thank the National Council for Scientific and Technological Development (CNPq) for financially supporting authors R.C. Pena, R. Andreazza and M.R.F. Guimarães; CNPq and the Research Foundation of the State of Minas Gerais (FAPEMIG) for financially supporting E.S. Tuelher and Research and Projects Financing (FINEP) for supporting this project.

\section{References}

Abbott WS (1925) A method of computing effectiveness of an insecticide. J Econ Entomol 18:265-267

Ali MI, Young SY, Felton GW, McNew RW (2002) Influence of the host plant on occluded virus production and lethal infectivity of a baculovirus. J Invert Pathol 81:158-165

Barreto MR, Guimarães CT, Teixeira FF, Paiva E, Valicente FH (2005) Effect of Baculovirus spodoptera isolates in Spodoptera frugiperda 
(J.E. Smith) (Lepidoptera: Noctuidae) larvae and their characterization by RAPD. Neotrop Entomol 34:67-75

Chapman JW, Williams T, Escribano A, Caballero P, Cave RD, Goulson D (1999) Age-related cannibalism and horizontal transmission of a nuclear polyhedrosis virus in larval Spodoptera frugiperda. Ecol Entomol 24:268-275

Cruz I, Figueiredo MLC, Valicente FH, Oliveira AC (1997) Application rate trials with a nuclear polyhedrosis virus to control Spodoptera frugiperda (Smith) on maize. An Soc Entomol Brasil 26:145-152

Cruz I, Gonçalves EPG, Figueiredo MLC (2002) Effect of a nuclear polyhedrosis virus on Spodoptera frugiperda (Smith) (Lepidoptera: Noctuidae) larvae, its damage and yield of maize crop. R Brasil Milho Sorgo 1:20-27

Elgar MA, Crespi BJ (1992) Cannibalism: ecology and evolution among diverse taxa. Oxford University Press, Oxford, pp 121-123, 361p

Farrar RR Jr, Ridgway RL (2000) Host plant effects on the activity of selected nuclear polyhedrosis virus against the corn earworm and beet armyworm (Lepidoptera: Noctuidae). Environ Entomol 29:108-115

Federici BA (1999) Naturally occurring baculoviruses for insect pest control. In: Hall FR, Menn JJ (eds) Methods in biotechnology: biopesticides, use and delivery, v.5. Humana Press, Totowa, pp 301-320

Fuxa JR (1991) Insect control with baculoviruses. Biotechnol Adv 9:425-442

Gardner WA, Fuxa JR (1980) Pathogens for the suppression of the fall armyworm. Flo Entomol 63:439-447

Goulson D, Cory JS (1995) Responses of Mamestra brassicae (Lepidoptera: Noctuidae) to crowding: interactions with disease resistance, color phase and growth. Oecol 104:416-423

Hodgson DJ, Vanbergen AJ, Hartley SE, Hails RS, Cory JS (2002) Differential selection of baculovirus genotypes mediated by different species of host food plant. Ecol Letters 5:512-518

Hunter-Fujita FR, Entwistle PF, Evans HF, Crook NE (1998) Insect viruses and pest management. Wiley, West Sussex

Li SY (2005) Virulence of a nucleopolyhedrovirus to Neodiprion abietis (Hymenoptera: Diprionidae). J Econ Entomol 98:1870-1875
Moscardi F, Leite LG, Zamataro CE (1997) Production of nuclear polyhedrosis virus of Anticarsia gemmatalis Hubner (Lepidoptera: Noctuidae): effect of virus dosage, host density and age. An Soc Entomol Brasil 26:121-132

Pierce NE (1995) Predatory and parasitic Lepidoptera: carnivores living on plants. J Lepidop Society 49:412-453

Raymond B, Vanbergen A, Pearce I, Hartley SE, Cory JS, Hails RS (2002) Host plant species can influence the fitness of herbivore pathogens: the winter moth and its nucleopolyhedrovirus. Oecol 131:533-541

Reed DJ, Begon M, Thompson DJ (1996) Differential cannibalism and population-dynamics in a host-parasitoid system. Oecol 105:189193

Reeson AF, Wilson K, Cory JS, Hankard P, Weeks JM, Goulson D, Hails RS (2000) Effects of phenotypic plasticity on pathogen transmission in the field in a Lepidoptera-NPV system. Oecol 124:373-380

Santiago-Alvarez C, Ortiz-Garcia R (1992) The influence of host plant on the susceptibility of Spodoptera littoralis (Boisd.) (Lep., Noctuidae) larvae to Spodoptera littoralis NPV (Baculovirus, Baculoviridae). J Appl Ent 114(1992):124-130

SAS Institute Inc (1999) SAS OnlineDoc ${ }^{\circledast}$, version 8. SAS Institute Inc, Cary

Shapiro M (1986) In vivo production of baculoviruses. In: Granados RR, Federici BF (eds) The biology of baculoviruses, vol 2. CRC Press, Boca Raton, pp 31-61

Valicente FH, Costa EF (1995) Controle da lagarta do cartucho, Spodoptera frugiperda (J.E. Smith), com o Baculovirus spodoptera, aplicado via água de irrigação. An Soc Entomol Brasil 24:61-67

Valicente FH, Barreto MR (2003) Bacillus thuringiensis survey in Brazil: geographical distribution and insecticidal activity against Spodoptera frugiperda (J. E. Smith) (Lepidoptera: Noctuidae). Neotropical Entomology 32:639-644

Valicente FH, Tuelher ES, Paiva CEC, Fellet MRG, Vieira CM, Wolff JLC (2008) A new baculovirus isolate that does not cause the liquefaction of the integument in Spodoptera frugiperda dead larvae. $\mathrm{R}$ Brasil Milho Sorgo 7:85-90 